\title{
Tribology of natural Poly-Ether-Ether-Ketone (PEEK) under transmission oil lubrication
}

\author{
Thiago Fontoura de Andrade ${ }^{*}$ (D), Helio Wiebeck² and Amilton Sinatora ${ }^{3,4}$ \\ ${ }^{1}$ Research and Development, Punch Powertrain, Sint-Truiden, Belgium \\ ${ }^{2}$ Departamento de Engenharia Metalúrgica e de Materiais, Escola Politécnica, Universidade de \\ São Paulo - USP, São Paulo, SP, Brasil \\ ${ }^{3}$ Laboratório de Fenômenos de Superfície - LFS, Departamento de Engenharia Mecânica, \\ Escola Politécnica, Universidade de São Paulo - USP, São Paulo, SP, Brasil \\ ${ }^{4}$ Instituto Tecnológico Vale, Vale S.A., Ouro Preto, MG, Brasil \\ *thiago.andrade@punchpowertrain.com
}

\begin{abstract}
High performance polymeric materials such as poly-ether-ether-ketone (PEEK) are increasingly being used for challenging tribological applications in order to replace metal parts in vehicle engines and transmissions. The tribology of natural PEEK, under oil-lubricated conditions, was studied for different metal counterbody finishes. Two different finishing processes were selected for this study: turning and polishing. The test system used was a tri-pin on disc, with pins made of PEEK and counterbodies made of steel, and then dipped in ATF Dexron VI oil. The conclusion was that the wear rate generated by turning was about seven times as high as the wear rate generated by polishing. The friction coefficient displayed a direct correlation with the lubrication regime, and the level of counterbody roughness. On average, the friction coefficient on the hydrodynamic regime for polishing was more than 3 times lower than the friction coefficient in the boundary regime for turning.
\end{abstract}

Keywords: tribology, PEEK, roughness, wear, friction.

How to cite: Andrade, T. F., Wiebeck, H., \& Sinatora, A. (2019). Tribology of natural Poly-Ether-Ether-Ketone (PEEK) under transmission oil lubrication. Polimeros: Ciência e Tecnologia, 29(2), e2019026. https://doi.org/10.1590/01041428.14416

\section{Introduction}

Poly(ether-ether-ketone) (PEEK) is a semicrystalline polymer, first mentioned in the literature in the early 1980 's ${ }^{[1]}$. It has high melt and glass transition temperatures $\left(\mathrm{Tm}=340{ }^{\circ} \mathrm{C}, \mathrm{Tg}=143{ }^{\circ} \mathrm{C}\right)$, high mechanical properties, excellent chemical resistance and melt and machining processability $^{[2]}$. Furthermore, PEEK is known for its excellent tribological properties ${ }^{[3]}$.

PEEK provides advantages such as relatively low friction and low wear rate for many tribological applications ${ }^{[4]}$. Many investigations on the friction and wear properties of PEEK, and its composites, have been performed. Cirino et al. ${ }^{[5]}$ reported PEEK behavior to abrasive wear; Voss et al. ${ }^{[6]}$ investigated the behavior of sliding and abrasive wear at room temperature, and Friedrich et al. ${ }^{[7]}$ examined the effect of counterpart roughness and temperature in relation to PEEK friction and wear.

Most tribological studies related to PEEK friction and wear in the literature were performed exclusively on dry environments ${ }^{[7-11]}$. However, it has been established that, in general, the interfacial environment considerably changes the effects of friction in polymers.

Zeng et al. ${ }^{[10]}$ pointed out both the beneficial and harmful effects of water on the friction and wear performance of reinforced polymers. Water inhibits buildup of transfer film; it may also penetrate and corrode the fiber-matrix interface. On the other hand, the role of water in decreasing frictional heat and reducing contact temperature was considerably pronounced, thus preserving the properties of the polymer such as stiffness, fatigue life and strength of the contact surface. The second beneficial effect of water is that it removes debris from the frictional region, thereby reducing abrasive wear, and ultimately improving the effect of carbon fiber polishing of the counterbody, in order to reduce surface roughness and wear.

However, the tribological behavior of PEEK under lubrication, with diesel and motor or transmission oil, has rarely been reported. Zhang et al. ${ }^{[12]}$ have studied the frictional and wear properties of pure PEEK and PEEK composites immersed in diesel and motor oil submitted to sliding against steel counterbodies. It has been shown that, in mixed and boundary lubrication regimes, the structure of the materials tested significantly affected tribological performance. The addition of diesel reduced friction and wear rates of pure PEEK. In the case of PEEK composites containing carbon fiber, ceramic particles and solid lubricants, addition of $2 \mathrm{uL} / \mathrm{h}$ diesel significantly increased friction and 
wear, as it inhibited buildup of high-performance transfer film. However, an increased flow of diesel gradually decreases friction and wear. In tests conducted with motor oil, the Stribeck curve demonstrates that, increments in sliding speed result in increased hydrodynamic action, thereby diminishing the friction coefficient. Another effect observed under this condition was a reduction or inhibition in counterbody film transfer buildup.

In view of the lack of studies about the wear morphology and friction behavior of PEEK under oil lubrication, the objective of the present work was to evaluate the friction and wear behavior of natural PEEK in lubricated environments, and with different levels of metal counterbody roughness.

\section{Materials and Methods}

\subsection{Friction test}

Polymer behavior regarding friction and wear was analyzed using a three-pin on metal disc tribometer sliding unidirectionally (Figure 1). The three-point contact was used to provide greater rotation speed stability in the test. The tribological results obtained from three-pin on disc test machines are generally different from those obtained from single-pin test machines. Single-pin tests tend to display stick-slip and preferential wear of pin edges. Three-pin on disc systems are particularly more suitable for the study of roughness on wear as they maintain contact surface fairly constant, after initial running-in ${ }^{[10]}$.

The present study was conducted using Victrex 151G-type PEEK $^{[1]}$. 5-mm-diameter pins were injected, per ASTM G99-0 $4^{[13]}$, at a temperature of approximately $380^{\circ} \mathrm{C}$. The friction surface was smoothly polished for 3 minutes using $0.5-\mu \mathrm{m}$ sandpaper in order to reduce remnant rough edges from injection molding, and to correct friction surface flatness. The counterbody consists of a disc, made of SAE 8620 steel, submitted to carburizing, quenching and tempering to a surface hardness range of 58-63 HRC.
After heat treatment, the counterbody surface was finished by means of two different processes: turning and polishing.

The test was conducted with all pins completely immersed in ATF Dextron VI oil, at a temperature of $85 \pm 5^{\circ} \mathrm{C}$ inside the test chamber. The dynamic viscosity at $30^{\circ} \mathrm{C}$ and $85^{\circ} \mathrm{C}$ was $36.3 \mathrm{cP}$ and $6.35 \mathrm{cP}$ respectively. For each test, all three pins were replaced. The pins were positioned $120^{\circ}$ apart, and then moved on the same track. Normal force was applied via a piezo-actuator on a servo-controlled mechanism. The capacitive sensor enabled continuous monitoring and comparison of the normal and nominal force of approximately $118 \mathrm{~N}$ (equivalent to an apparent contact pressure of $2 \mathrm{MPa}$ ), so that any variations could be immediately corrected. Rotational speed was $125 \mathrm{rad} / \mathrm{s}$, which corresponds to a linear speed of $2 \mathrm{~m} / \mathrm{s}$, also kept constant throughout the test. Test duration was determined after evaluation of wear for different sliding periods until the wear rate remained constant. As a result, we adopted a 120-minute period. All tests were repeated at least three times.

\subsection{Assessment of Wear}

The specific wear rate $\left(W_{S}\right)$ expressed by Equation 1 was calculated via material mass loss $(\Delta \mathrm{m})$, by measuring the difference in pin mass before and after the test, divided by the load $(F)$, sliding distance $(L)$ and material density $(\rho)$.

$$
W_{s}=\frac{\Delta m}{F L \rho}\left(\frac{m^{3}}{N m}\right)
$$

\subsection{Roughness measurements}

A white light interferometer (Zygo Nexview) was used to measure roughness. Figure 2 shows the typical topography of each finishing studied. The mean linear roughness parameters are shown in Table 1. These parameters were calculated perpendicular to the sliding direction. Four measurements were carried out for each sample, $90^{\circ}$ apart.

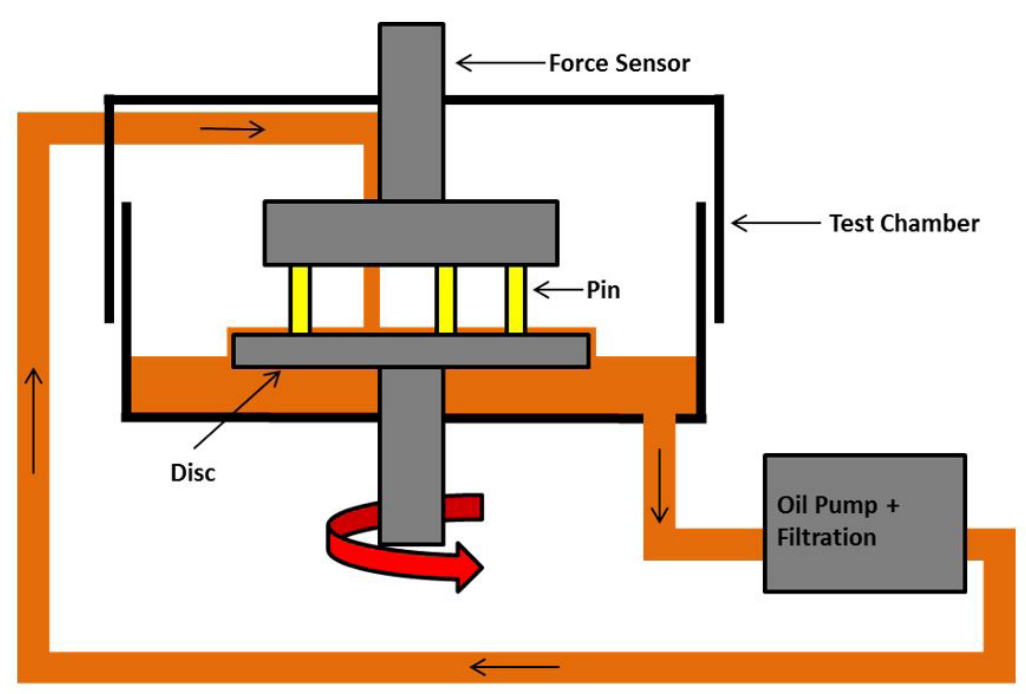

Oil circulation

Figure 1. Diagram of tri-pin on disc apparatus. 

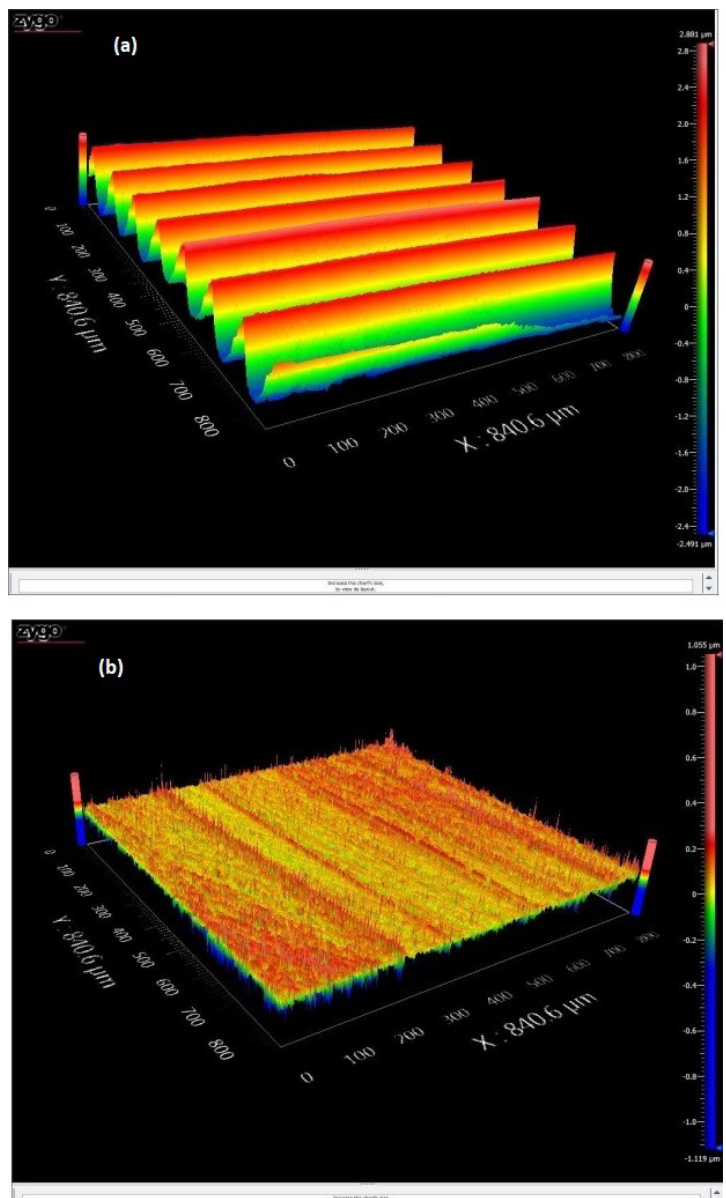

Figure 2. Typical disc surface roughness measurements for three test repetitions; (a) turning and (b) polishing.

Table 1. Values for surface roughness for each steel counterbody finishing: roughness average (Ra), root mean square (RMS), and total roughness $(\mathrm{Rz})$.

\begin{tabular}{cccc}
\hline Finishing Process & Ra $(\boldsymbol{\mu m})$ & RMS $(\boldsymbol{\mu m})$ & $\mathbf{R z}(\boldsymbol{\mu m})$ \\
\hline Turning & $1.264 \pm 0.010$ & $1.477 \pm 0.013$ & $6.340 \pm 0.149$ \\
Polishing & $0.048 \pm 0.003$ & $0.063 \pm 0.004$ & $0.575 \pm 0.096$ \\
\hline
\end{tabular}

\subsection{Microscopic characterization of wear properties}

After gold sputtering, the frictional surfaces were examined via scanning electron microscopy (SEM), on a FEI Inspect F50 microscope. Energy dispersive X-ray analysis (EDX) was also used in SEM investigations in order to check whether particles were embedded in the friction surfaces.

\section{Results and Discussion}

\subsection{Friction surface characterization before test}

Pins made of natural PEEK were submitted to mechanical polishing, and their surfaces were characterized as shown in Figures 3-5. Figure 3 shows a 50-x magnification of the pin friction surface, after being prepared for the test. Figure 4 and 5 show the friction surface via scanning electron microscopy. The injection molded pins were polished to eliminate

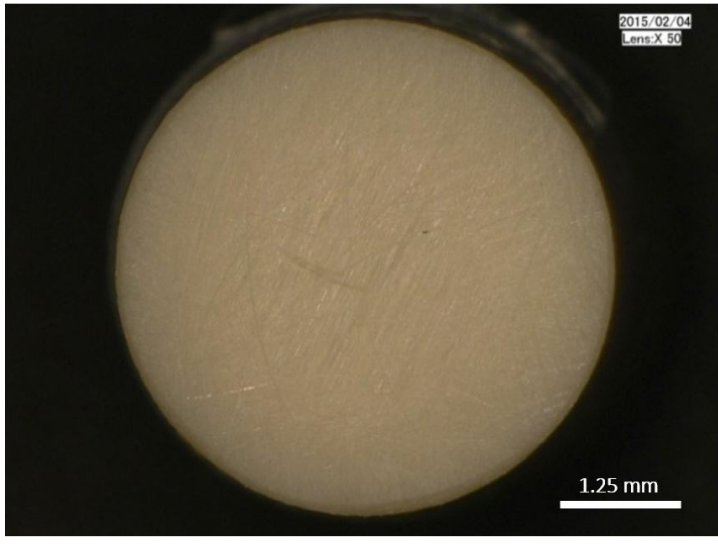

Figure 3. Friction surface of the natural PEEK pin before testing.

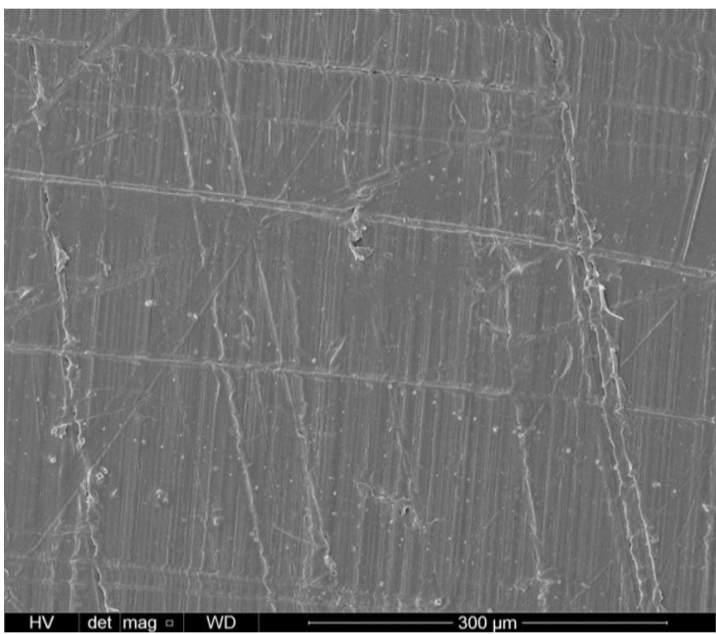

Figure 4. Aspect of a sample of natural PEEK before the test, with abrasion wear marks across the friction surface of the pin.

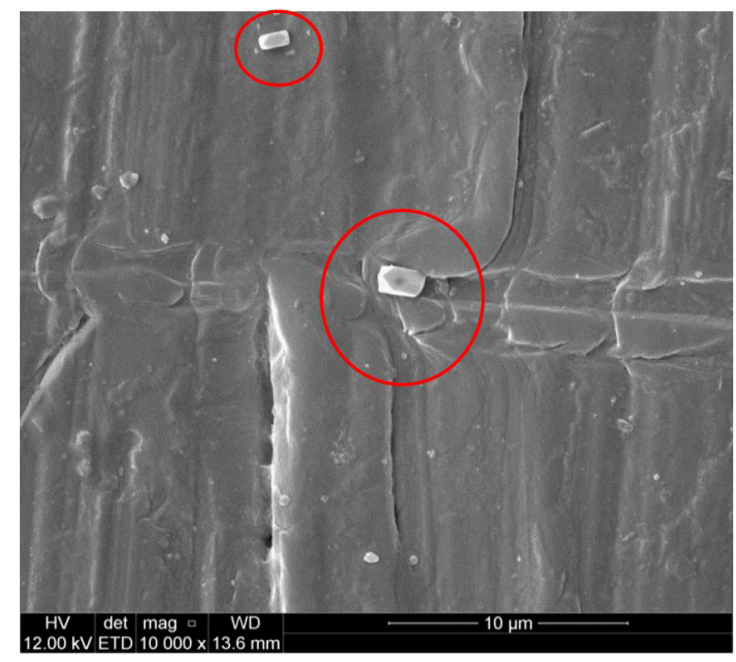

Figure 5. Contaminants from the polishing system circled in red. 
burrs, but this process caused some abrasion marks due to contaminants in the polishing system. Such contaminants were identified, via EDX, as potassium chloride, as shown in Figure 6. The surface topography condition before the wear tests is important in order to avoid misinterpretation of the wear mode after sliding.

\subsection{Wear mechanism of the pair PEEK/polishing counterbody}

In order to determine the predominant wear mechanism, worn surfaces were analyzed via SEM. After sliding against the polished counterbody, the PEEK pin displayed no apparent sliding marks. Figure 7 shows wear morphology after 120 minutes. Figure 7 b) and c) show the rounded edges of grooves formed during the preparation of the sample, and round-shaped debris. As the general aspect of the friction surface was very similar before and after the tests, it was not possible to identify sliding direction. This is evidence of hydrodynamic lubrication regime for most of the duration of the test. Apparently, the debris originated from the edges of the existing grooves. It could be hypothesized that the debris were formed by fatigue, probably caused by the oil film flowing between the sliding tribological pair $^{[12]}$. Another possible explanation would be that, while sliding, the groove edges at the pin surface collided with counterbody asperities, despite oil film separation of the surfaces. The repeated collisions caused fatigue and the corresponding edges were ultimately eliminated from the matrix. Thus, debris and fractured regions or holes formed in the worn surface (Figure $7 \mathrm{c}$ and $\mathrm{d}$ ). The debris can contribute to abrasion of the pins in the following sliding process, and be incorporated into the polymer bulk once again, or be transferred to the counterbody ${ }^{[12]}$.

\subsection{Wear mechanism of the pair PEEK/Turning counterbody}

Counterbody surface roughness, produced by the turning finishing, changed the tribological behavior of natural PEEK. The test of the PEEK pin against turned steel surface was conducted under the same pressure and speed as the test with the polished disc. Figure 8 shows the wear morphology of the pin, at different magnifications, analyzed via SEM, after the 120-minute test, under oil lubrication. Figure 8a) shows how the metal counterbody abraded the plastic pin, forming its topography on the plastic friction surface. This indicates direct pin/disc contact, and a continuous wear process.

Figure $8 b$ ) displays peaks and valleys on the friction surface of the pin, similar to counterbody topography. Yellow arrows show shallow pits formed by fatigue. The surface observed in Figure 8c) and d) indicates the presence of microgrooves combined with wear morphology similar to aligned ripples or wavy folds, repeatedly formed, and perpendicular to the sliding direction. This demonstrates the viscoelastic behavior of natural PEEK ${ }^{[14]}$. When the pin touches the rigid asperities of the steel counterbody, and slips, under pressure and speed conditions, the molecules of the polymer are deformed and tend to align in the direction of the deformation. The alignment and relative movement between the amorphous portion of polymer molecules, and the accommodation by the deformation mechanism, results in a low elastic modulus; $3.7 \mathrm{GPa}$, typical for natural $\mathrm{PEEK}^{[10,15]}$. In solid contact with a rough surface, the low modulus of elasticity has two effects. The first effect is that the true area of contact is very close to the apparent contact area. The second is a considerable tangential movement, parallel to the sliding direction, without excessive release of wear debris ${ }^{[16]}$. This sliding mechanism works on the principle that a large portion of the polymer surface is strongly connected to the opposing surface. This connection takes place due to Van de Waals forces and hydrogen bonds ${ }^{[17]}$. The formation and rupture of such bonds control the friction adhesion component. This process is known as "stick-slip", and due to adhesion forces at the surface, there is no relative movement between the bonded surfaces, even when the tangential movement is sufficient to break the metal / polymer connection, leading to development of ripples or wavy folds wear patterns ${ }^{[18,19]}$. Such surface characteristics occur under the boundary lubrication regime. The findings suggest that the wear mechanism is a

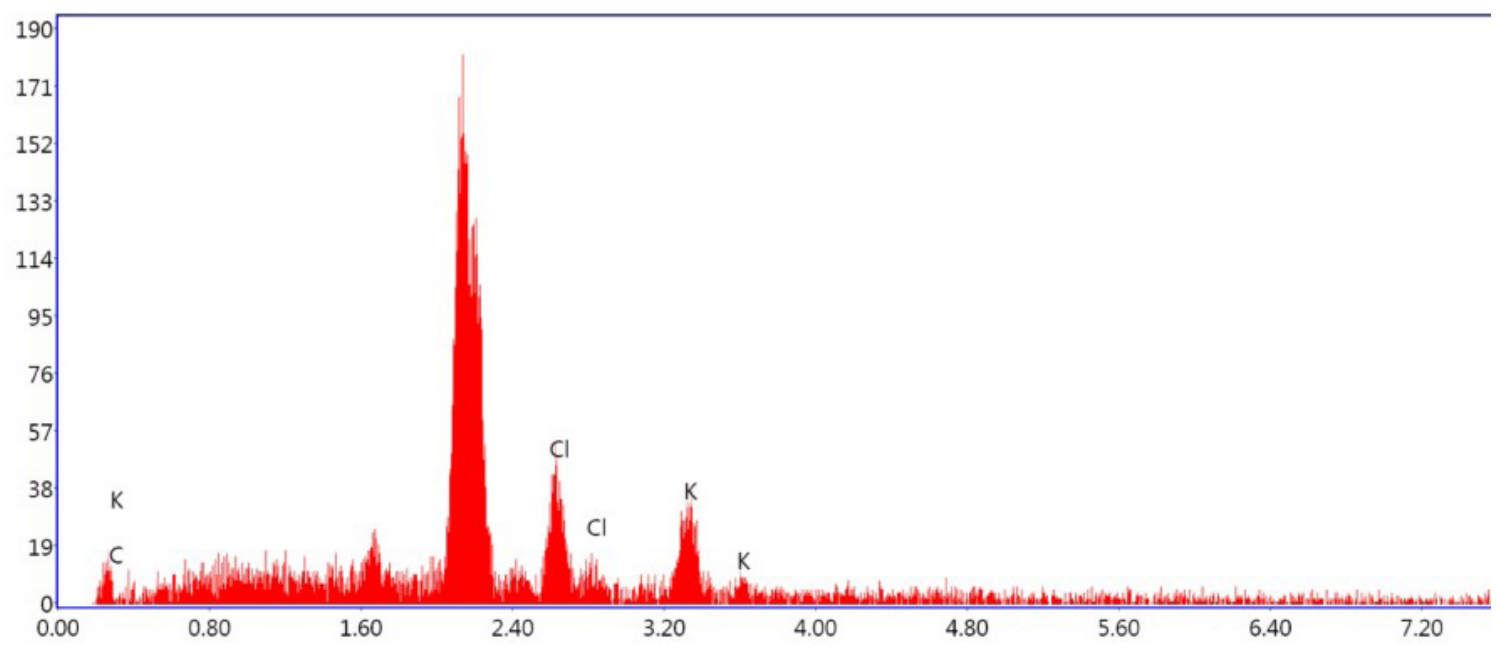

Figure 6. Potassium chloride contamination, as seen in Figure 4, identified by EDS. 


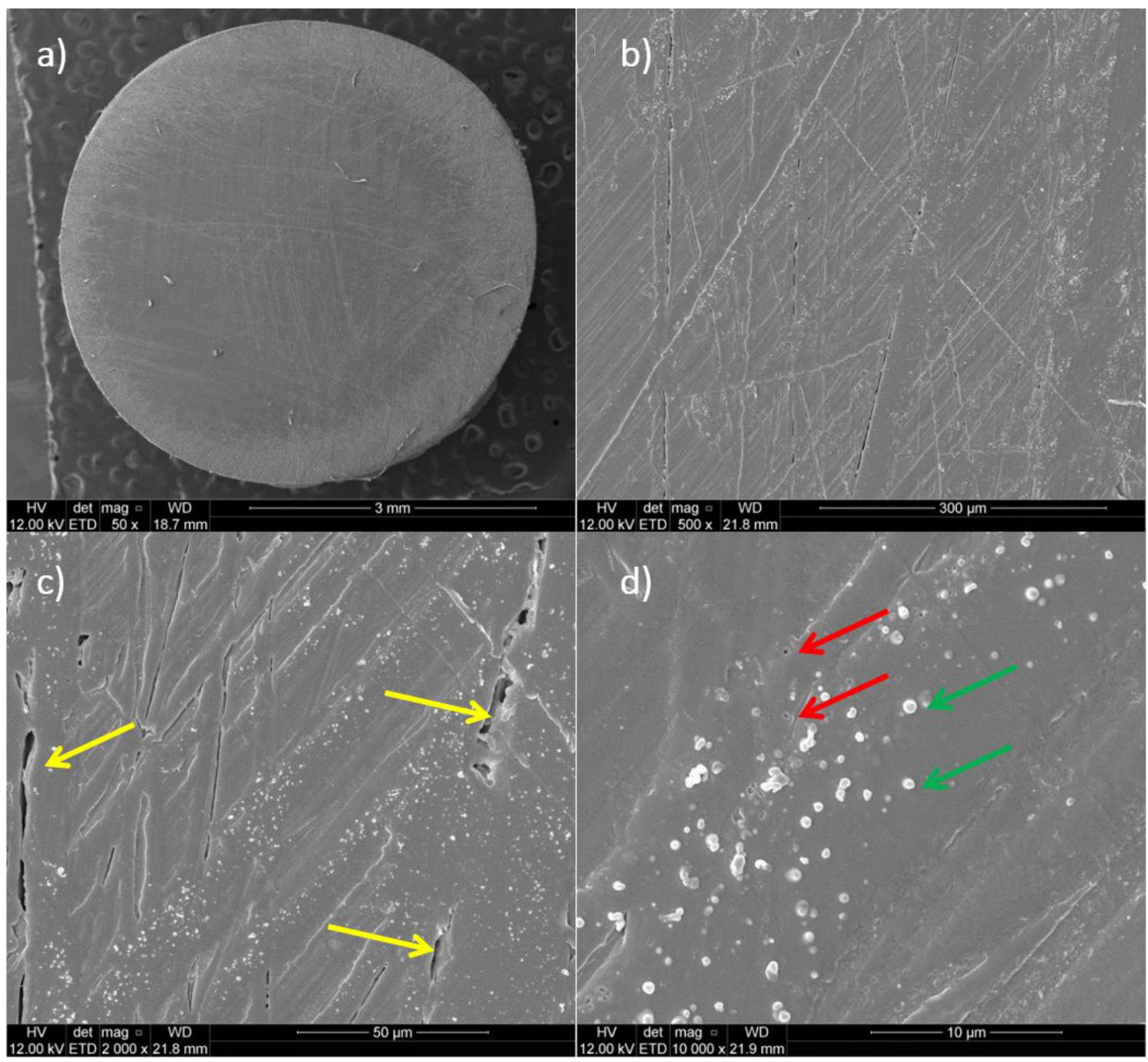

Figure 7. Morphology of natural PEEK pin wear tested against a polished counterbody. a) friction surface similar to the pre-test state; b) grooves produced during sample preparation; c) Yellow arrows point to fractures where debris formed; d) rounded debris are shown by green arrows. Red arrows point to holes on the friction surface.

combination of adhesion and abrasion ${ }^{[9,20]}$. Another factor that increases the adhesive / abrasive wear component is the presence of massive amounts of chip-type debris, generated at the very tip of the sliding pin, as shown by the yellow arrows in Figure 9. The wear mechanism that creates this type of debris can be defined as "transfer mode", in which the interfacial bonding between the sliding pair is stronger than the cohesive strength of PEEK ${ }^{[21]}$. In this case, PEEK can be gradually transferred to the surface of the metal disc. Then, the material accumulated on the surface of the counterbody is removed in the form of flakes ${ }^{[12]}$.

Zhang et al. ${ }^{[22]}$ studied the effect of lubrication with diesel oil in natural PEEK and found that, under dry sliding, parallel grooves tend to form in the sliding direction; therefore, the abrasion mechanism by metal asperities is important. However, wear morphology changes when the tribosystems are lubricated with diesel oil. Fewer grooves are formed on the surface of the PEEK pin during boundary lubrication.
This indicates that when diesel oil is present in the wear track, the effect of abrasion is attenuated, compared to dry sliding condition. On the other hand, the addition of diesel oil, as well as the use of ATF Dexron VI Oil, marked the onset of ripple-type wear patterns. The increased amount of diesel oil also incremented the number of ripple-type patterns. It is believed that these types of wear patterns occur when the adhesion component is greater than abrasion, under a boundary lubrication regime ${ }^{[23,24]}$.

\subsection{Wear rate and friction coefficient}

To illustrate the contrast between polishing and turning, Figure 10 shows the values of specific wear rates as a function of metal disc roughness. For measurements made with natural PEEK, wear rates were approximately seven times higher for turning $\left(2.664 \pm 0.708 \times 10^{-7} \mathrm{~mm}^{3} / \mathrm{Nm}\right)$ than for polishing finishing $\left(0.411 \pm 0.242 \times 10^{-7} \mathrm{~mm}^{3} / \mathrm{Nm}\right)$. 


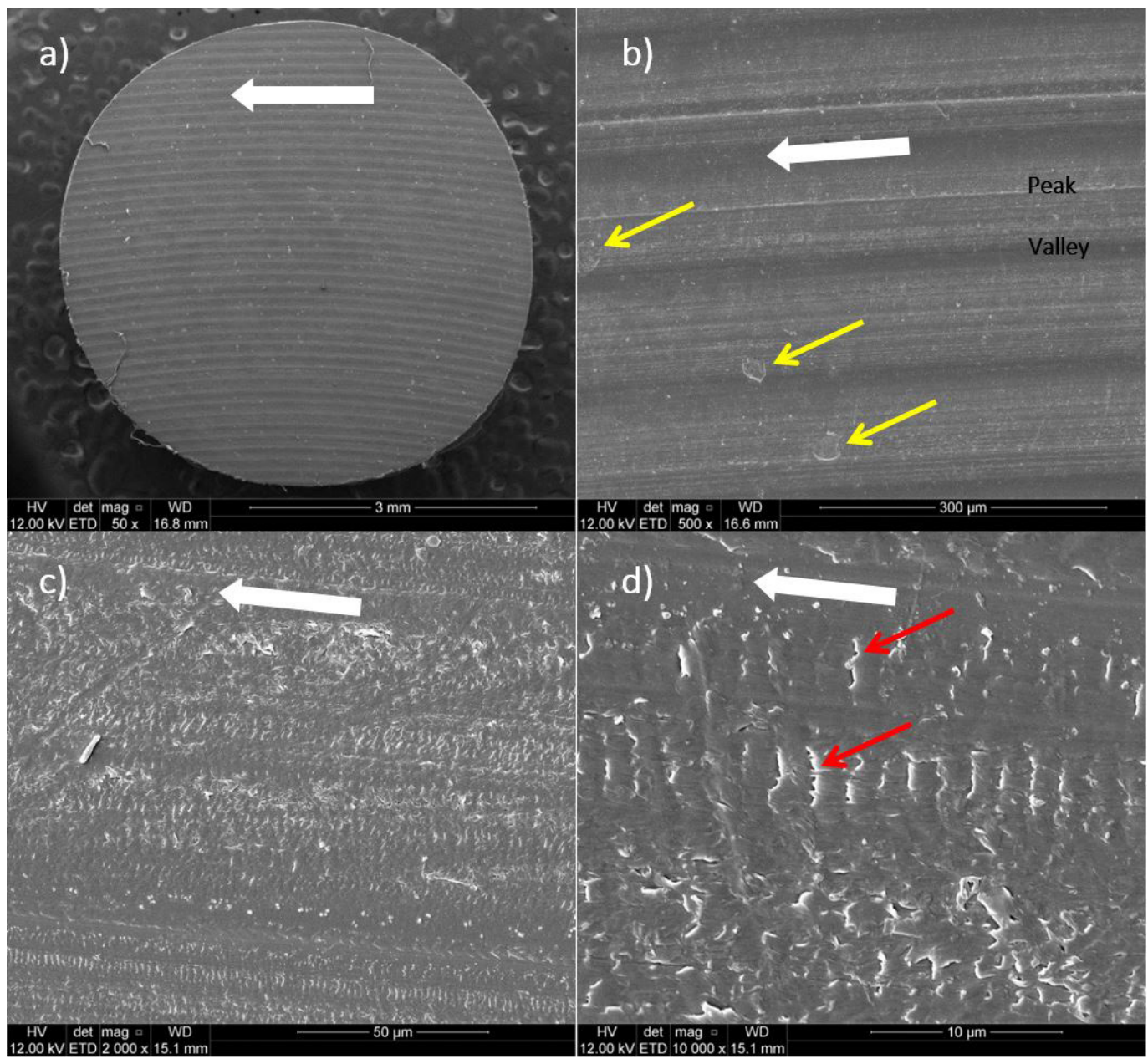

Figure 8. Morphology of a pin made of natural PEEK worn against turned counterbody. The white arrows indicate the sliding direction; a) Grooves generated by harder asperities of the counterbody; b) The yellow arrows indicate shallow pits formed by fatigue, c) Presence of vertical ripple-type patterns towards the slip direction; d) The red arrows show the morphology and the repetitive pattern of the ripples.

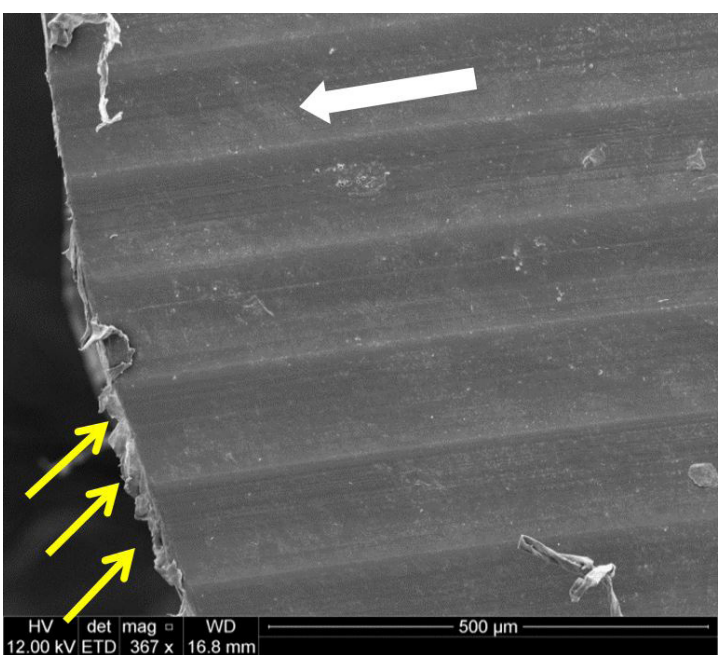

Figure 9. Surface of a pin made of natural PEEK tested against turning disc. Yellow arrows indicate the debris produced by material displacement caused by the tangential force during sliding. The white arrow shows sliding direction.
This result reflects the wear mechanism observed in scanning electron microscopy. When rubbed against the polished surface, natural PEEK produced less debris, formed by fatigue, probably due to the action of the oil film flux between the tribological pair during sliding. The turned surface produced much more debris due to cohesive wear abrasion and adhesion, which produced a higher specific wear rate than the polished surface.

Figure 11 shows the behavior of the friction coefficient of PEEK as a function of test time for turning and polishing. The average friction coefficient for turning was $0.121 \pm 0.009$, whereas for polishing it was approximately $0.0347 \pm 0.003$. In general, it was possible to ascertain that the friction coefficient increases as surface roughness increases. Greenwood and Williamson $^{[25]}$ initially proposed that when two surfaces slide over each other, friction comes from the shear stress generated by plowing caused by counterpart asperities. In the case of the turned surface, clearly there was contact between the pin and disc; however, for the polishing finish, there is evidence that an oil film separated the tribological pair. Thus, the friction coefficient measured derives primarily from the viscous shear flow of the lubricant. 
For the polymer-metal contact, friction can be attributed to two sources: deformation, which involves relatively large energy dissipation around the contact area of the polymer, and adhesion at the friction surface between

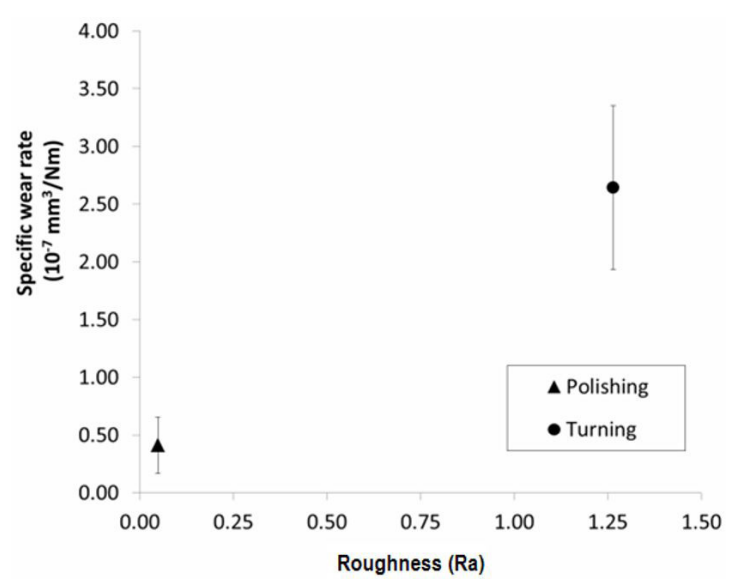

Figure 10. Effect of counterbody roughness on specific wear rate of the pin made of natural PEEK. the metal and the polymer ${ }^{[17]}$. The friction coefficient of PEEK/turning disc above 0.14 , obtained at the start of the test, may be due to strong contribution of the adhesion mechanism of PEEK, which was highly deformed by the asperities on the turning disc. The high loss of hysteresis and internal energy dissipation can account for the high friction coefficient in the natural PEEK condition. This is confirmed by evidence of adhesive wear (wavy folds) observed in wear morphology ${ }^{[12]}$. During the test, when the pins were wearing out, the friction coefficient decreased due to increased contact area, and reduction of the adhesive wear component through a decrease in the pressure applied. This resulted in improved lubrication, with a friction coefficient of 0.12 , after 90 minutes. Another factor that could have led to a reduced friction coefficient was the buildup of a tribofilm on the counterbody friction track. This occurs when the shear plane is changed from the steel surface to the polymer layer formed on the metal surface ${ }^{[12]}$. The tribofilm is produced as a result of a PEEK film being transferred to the counterbody through tribochemical reactions, such as the formation of organometallic compounds ${ }^{[26]}$. However, scanning electron microscopy did not show such tribofilm. Figure 12 shows the surface of a turned counterbody analyzed via backscattered electron technique. The characterization a)

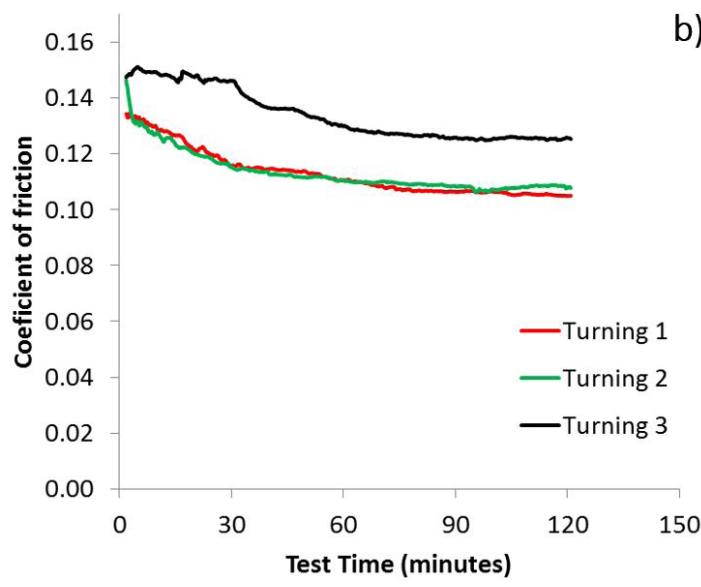

b)

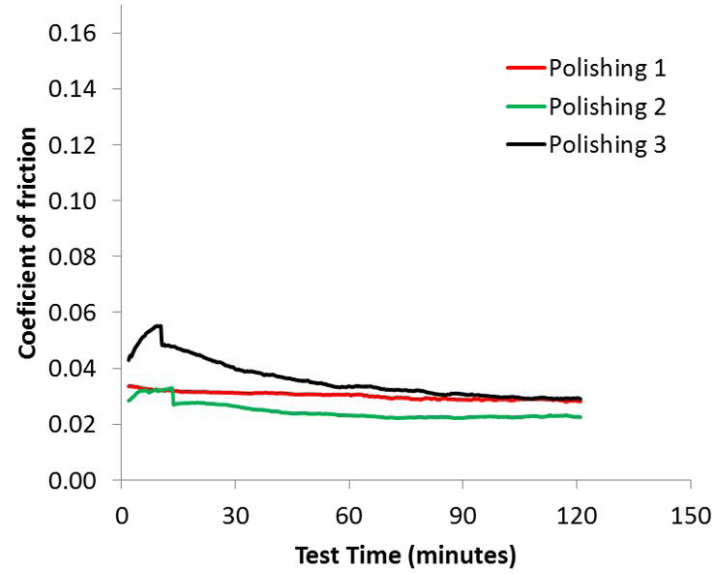

Figure 11. Results of friction tests conducted for the two different finishes studied regarding PEEK. a) turning and b) polishing.

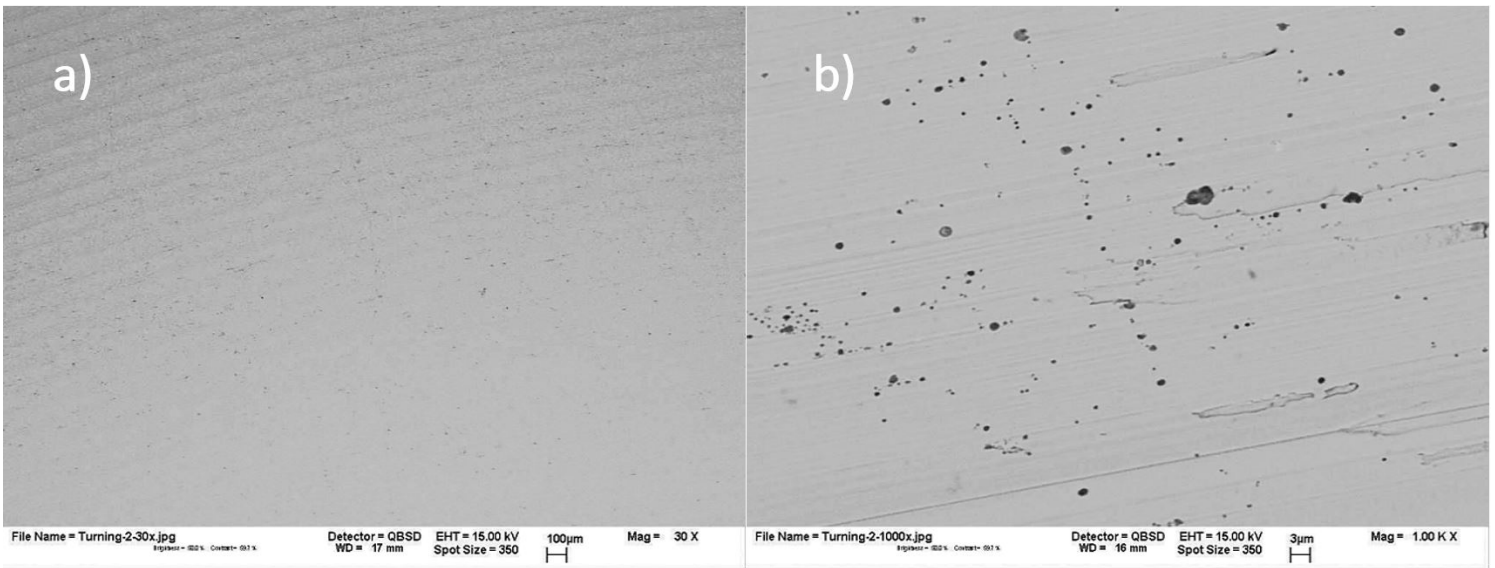

Figure 12. Steel counterbody surface analyzed by electron backscatter technique; a) 30-x magnification; b) 1,000-x magnification. 
of a tribofilm structure is complex because the film is extremely thin. Scherge et al. ${ }^{[27]}$ measured the PA 46 transfer film layer formed on the metal counterbody, after sliding in a lubricated environment, through autoradiography and $\mathrm{X}$-rays photoelectron spectroscopy. The key indicator to measure the thickness of the polymer film was the concentration of nitrogen that helped determine a $160-\mathrm{nm}$ layer. The polymer chain of PEEK does not include nitrogen, but the concentrations of oxygen and carbon can be used in a future study.

\section{Conclusions}

Natural PEEK showed great potential for application in vehicle powertrain parts in oil-lubricated environments. The wear rate for both finishes tested is below $10^{-6} \mathrm{~mm}^{3} / \mathrm{Nm}$, which enables the use of Natural PEEK for engineering applications. The results obtained with natural PEEK under sliding wear condition, for polished and turned counterbody finishings, can be summarized as follows:

- The wear mechanism for the PEEK pin was fatigue of groove edges while sliding against a polished counterbody. On the other hand, the wear mechanism seen for the PEEK pin/turned counterbody pair was a combination of abrasion and adhesion.

- The wear rate was seven times higher for turning than for polishing under the conditions tested.

- The friction coefficient for turning was more than 3 times that of polishing.

- The lubrication regime for the PEEK/polished counterbody pair was hydrodynamic, whereas for the PEEK/turned counterbody it was boundary.

\section{Acknowledgements}

The authors wish to thank Mr. Ricardo Elhke and Mr. Kida Kazuhiro from Victrex for kindly supplying the polymeric material, as well as the test benches, and for their invaluable technical input.

\section{References}

1. Attwood, T. E., Dawson, P. C., Freeman, J. L., Hoy, L. R. J., Rose, J. B., \& Staniland, P. (1981). Synthesis and properties of polyaryletherketones. Polymer, 22(8), 1096-1103. http:// dx.doi.org/10.1016/0032-3861(81)90299-8.

2. Gutiérrez, J. C., Rubio, J. C. C., \& Faria, E. (2014). Usinabilidade de materiais compósitos poliméricos para aplicações automotivas. Polímeros. Ciência e Tecnologia, 24(6), 711-719.

3. Friedrich, K., Karger-Kocsis, J., \& Lu, Z. (1991). Effects of steel counterface roughness and temperature on the friction and wear of PEEK composites under dry sliding conditions. Wear, 148(2), 235-247. http://dx.doi.org/10.1016/00431648(91)90287-5.

4. Ramachandra, S., \& Ovaert, T. C. (1997). The effect of controlled surface topoghaphical features on the unlubricated transfer nad wear of PEEK. Wear, 206(1-2), 94-99. http:// dx.doi.org/10.1016/S0043-1648(96)07354-1.

5. Cirino, M., Friedrich, K., \& Pipes, R. (1988). Evaluation of polymer composites for sliding abrasive wear applications.
Composites, 19(5), 383-392. http://dx.doi.org/10.1016/00104361(88)90126-7.

6. Voss, H., \& Friedrich, K. (1987). On the wear behaviour of short frbre-reinforced PEEK composite. Wear, 116(1), 1-18. http://dx.doi.org/10.1016/0043-1648(87)90262-6.

7. Friedrich, K., Karger-Kocsis, J., \& Lu, Z. (1991). Effects of steel counterface roughness and temperature on the friction and wear of PEEK composites under dry sliding conditions. Wear, 148(2), 235-247. http://dx.doi.org/10.1016/00431648(91)90287-5.

8. Lu, Z. P., \& Friedrich, K. (1995). On sliding friction and wear of PEEK and its composites. Wear, 181-183(2), 624-631.

9. Ma, N., Lin, G. M., Xie, G. Y., Sui, G. X., \& Yang, R. (2012). Tribological behavior of polyetheretherketone composites containing short carbon fibers and potassium titanate whiskers in dry sliding against steel. Journal of Applied Polymer Science, 123(2), 740-748. http://dx.doi.org/10.1002/app.34502.

10. Zeng, H., He, G., \& Yang, G. (1987). Friction and wear of poly(phenylene sulphide) and its carbon fibre composites: I unlubricated. Wear, 116(1), 59-68. http://dx.doi.org/10.1016/00431648(87)90267-5.

11. Wang, Q., Xu, Q. J., Shen, W., \& Xue, Q. (1997). The effect of nanometer $\mathrm{SiC}$ filler on the tribological behavior of PEEK. Wear, 209(1-2), 316-321. http://dx.doi.org/10.1016/S00431648(97)00015-X.

12. Zhang, G., Wetzel, B., \& Wang, Q. (2015). Tribological behavior of PEEK-based materials under mixed and boundary lubrication conditions. Tribology International, 88, 153-161. http://dx.doi.org/10.1016/j.triboint.2015.03.021.

13. Zhang, G., Yu, H., Zhang, C., Liao, H., \& Coddet, C. (2008). Temperature dependence of the tribological mechanisms of amorphous PEEK (polyetheretherketone) under dry sliding conditions. Acta Materialia, 56(10), 2182-2190. http://dx.doi. org/10.1016/j.actamat.2008.01.018.

14. Victrex. (2014). Materials properties guide. Lancashire: Victrex PLC. Retrieved in 2017, March 10, from http://www.victrex. com.

15. American Society for Testing and Materials -ASTM (2004). ASTM G-99 04: standard test method for wear testing with pin-on-disk apparatus metals test methods and analytical procedure (Vol. 03.02; Section 3). West Conshohocken: ASTM

16. Elliott, D. M., Fisher, J., \& Clark, D. T. (1998). Effect of counterface surface roughness and its evolution on the wear and friction of PEEK and PEEK-bonded carbon fibre composites on stainless steel. Wear, 217(2), 288-296. http:// dx.doi.org/10.1016/S0043-1648(98)00148-3.

17. Zhang, G., Zhang, C., Nardin, P., Li, W. Y., Liao, H., \& Coddet, C. (2008). Effects of sliding velocity and applied load on the tribological mechanism of amorphous poly-ethr-ethr-ketone (PEEK). Tribology International, 41(2), 79-86. http://dx.doi. org/10.1016/j.triboint.2007.05.002.

18. Stachowiak, G. W., \& Batchelor, A. W. (2005). Engineering tribology. Amsterdam: Elsevier.

19. Friedrich, K. (1986). Mild wear of rubber-based compounds. In K. Friedrich (Ed.), Friction and wear of polymer composites (pp. 289-327). Amsterdam: Elsevier.

20. Schallamach, A. (1971). How does rubber slide? Wear, 17(4), 301-312. http://dx.doi.org/10.1016/0043-1648(71)90033-0.

21. Buckley, D. H. (1981). Surface effects in adhesion, friction, wear and lubrication. Amsterdam: Elsevier.

22. Zhang, G., \& Schlarb, A. K. (2009). Correlation of the tribological behaviors with the mechanical properties of poly-ether-etherketones (PEEKs) with different molecular weights and their fiber filled composites. Wear, 266(1-2), 337-344. http://dx.doi. org/10.1016/j.wear.2008.07.004. 
23. Aharoni, S. M. (1973). The wear of polymers by roll formation. Wear, 25(3), 309-327. http://dx.doi.org/10.1016/00431648(73)90002-1.

24. Myshkin, N. K., Petrokovets, M. I., \& Kovalev, A. V. (2005). Tribology of polymers: adhesion, friction, wear and mass transfer. Tribology International, 38(11-12), 910-921. http:// dx.doi.org/10.1016/j.triboint.2005.07.016.

25. Greenwood, J. A., \& Williamson, J. B. P. (1966). Contact of nominally flat surfaces. Proceedings of the Royal Society of London. Series A, Mathematical and Physical Sciences, 295(1442), 300-319. http://dx.doi.org/10.1098/rspa.1966.0242.

26. Tamura, J., Clarke, I. C., Kawanabe, K., Akagi, M., Good, V. D., Williams, P. A., Masaoka, T., Schroeder, D., \& Oonishi,
H. (2002). Micro-wear patterns on UHMWPE tibial inserts in total knee joint simulation. Journal of Biomedical Materials Research, 61(2), 218-225. http://dx.doi.org/10.1002/jbm.10027. PMid:12007202.

27. Scherge, M., Kramlich, J., Böttcher, R., \& Hoppe, T. (2013). Running-in due to material transfer of lubricated steel/PA46 (aliphatic polyamide) contacts. Wear, 301(1-2), 758-762. http:// dx.doi.org/10.1016/j.wear.2012.11.035.

Received: Mar. 10, 2017 Revised: Sept. 25, 2017 Accepted: Nov. 16, 2017 